\title{
A produção do espaço urbano na orla de Porto Alegre, Brasil
}

\section{The riverfront production of urban space: Porto Alegre, Brazil}

\author{
Clarice Misoczky de Oliveira \\ Universidade Federal do Rio Grande do Sul, Porto Alegre, Brasil.
} arq.clarice@gmail.com

\begin{abstract}
Resumo
O artigo tem como objetivo desvelar o processo de produção do espaço na Orla do Rio Guaíba na cidade de Porto Alegre, capital do Rio Grande do Sul - Brasil. O estudo se posiciona no campo dos Estudos Críticos Urbanos e tem como repertório fundamental o pensamento marxista a partir da obra de Henri Lefebvre. A análise dos dados se dá a partir dos conceitos de totalidade, realidade e alienação em conjunto com a tríade da produção do espaço que proporciona um movimento trialético entre o espaço concebido (dos técnicos, arquitetos e urbanistas), o espaço percebido (a prática espacial), com o espaço vivido (os espaços de dominação e/ou de transformação). $O$ argumento passa pela associação da ação do mercado imobiliário em relação a fundos de investimentos, a imagem da cidade via marketing urbano e do empreendedorismo urbano com a inovação tecnológica e a criação de espaços de consumo de lazer que operam na valorização do valor do espaço urbano construído. Ainda assim, grupos insurgentes por meio de ocupações e movimentos sociais se colocam no processo visando uma produção social do espaço urbano, ante a produção capitalista neoliberal.
\end{abstract}

Palavras-chaves: empreendedorismo urbano, financeirização, projetos urbanos, produção do espaço, Porto Alegre

\begin{abstract}
The paper aims to unveil the process of production of space on the Riverfront in the city of Porto Alegre, capital of Rio Grande do Sul - Brazil. The study is positioned in the field of Urban Critical Studies and its fundamental repertoire is Marxist thinking from the work of Henri Lefebvre. The data analysis takes place from the concepts of totality, reality and alienation together with the triad of the production of space that provides a trialetic movement between the conceived space (of the technicians, architects and urbanists), the perceived space (the spatial practice), with the lived space (the spaces of domination and / or transformation). The argument goes through the association of the action of the real estate market in relation to investment funds, the image of the city via urban marketing and urban entrepreneurialism with technological innovation and the creation of leisure consumption spaces that operate in valuing the value of the built environment. Even so, insurgent groups through occupations and social movements put themselves in the process struggling for a social production of urban space, against the neoliberal capitalist production.
\end{abstract}

Keywords: financialization, Porto Alegre, production of space, urban entrepreneurialism, urban projects.

Documento recibido el 30 de agosto de 2019 y aceptado el 22 de abril de 2020.

Este artículo participó en el Seminario Internacional "El Complejo Urbano Financiero-Inmobiliario en América Latina", realizado el jueves 4 y viernes 5 de abril de 2019, en Santiago de Chile, organizado y patrocinado en el marco del Proyecto Fondecyt Regular 1151287 - Investigador Principal: Ernesto López Morales, el Centro de Estudios del Conflicto y la Cohesión Social (COES), la Facultad de Arquitectura y Urbanismo de la Universidad de Chile y su Doctorado en Territorio, Espacio y Sociedad (D_TES).

Cómo citar: Misoczky de Oliveira, C. (2020). A produção do espaço urbano na orla de Porto Alegre, Brasil. Revista de Urbanismo, 42, 17-31. https://doi.org/10.5354/0717-5051.2020.54280 
A partir dos anos 1980, as práticas neoliberais foram apresentadas como a saída para crises fiscais. Para sua efetivação foi criado um amplo aparato regulatório acompanhado de transformação institucional e regulatória. No que diz respeito ao espaço urbano, o neoliberalismo se configura para além da liberalização dos mercados e da flexibilização das normas urbanísticas, mas pelas novas relações de produção de um mercado global financeirizado. Sob esta perspectiva, o artigo tem como objetivo desvelar o processo de produção do espaço na Orla do Rio Guaíba na cidade de Porto Alegre, capital do Rio Grande do Sul - Brasil.

Porto Alegre é conhecida mundialmente pela experiência pioneira do Orçamento Participativo da década de 1990. No entanto, nos últimos vinte anos práticas gerencialistas tem sido o foco das recentes gestões municipais. No que tange a área específica do estudo, a cidade que surgiu de sua relação com o Rio Guaíba com a chegada dos portugueses, ao longo de sua história, se desenvolveu sem relação direta com o Rio, se não por suas atividades portuárias. No entanto, o cenário de oportunidades para transformação desta área mudou por ocasião da realização do megaevento Copa do Mundo de Futebol, com o aporte de diversos recursos municipais para melhoria de infraestrutura urbana. Diversos são os autores que vinculam novas práticas de empreendedorismo urbano associadas a realização de megaeventos (Broudehoux, 2016; Hall, 2006; Klauser, 2011; McLeoad, 2002; Muller, 2011; Owen, 2002; Tomlinson, 2010).

A presente pesquisa parte da hipótese que por ocasião deste novo cenário, o interesse do mercado imobiliário migra para a área da Orla do Rio Guaíba, porém sob novas formas de produzir o espaço urbano. Se coloca, portanto, a seguinte pergunta: a atuação do mercado imobiliário ocorre nos moldes tradicionais, ou, novas estratégias de produção da cidade são incorporadas fomentadas pelo ideário do empreendedorismo e da inovação? Para responder esta pergunta, destaca-se alguns objetivos específicos, como: a identificação dos empreendimentos localizados ao longo da Orla do Guaíba, dos atores envolvidos, das fontes de recursos financeiros, das frentes de resistência, das estratégias de marketing etc.

Mas antes de serem apresentados metodologia e resultados da pesquisa, a seguir são abordados os antecedentes teóricos que servem como suporte a este estudo. Os conceitos principais são: o espaço urbano, em Lefebvre (2008a); o empreendedorismo urbano e o regime de acumulação flexível, de acordo com Harvey (2006 e 2011, respectivamente); e financeirização, em Krippner (2005); entre outros.

\section{Produção do espaço urbano e financeirização}

O sistema capitalista apresenta ao longo da história ciclos composto por crise, desenvolvimento econômico e acumulação capitalista. Neste desenrolar ocorreu a migração da priorização de investimentos do circuito primário para o circuito secundário. No circuito primário, o capital excedente era alocado nos meios de produção industrial, já no circuito secundário, aplicados na aquisição e produção de bens imobiliários e projetos urbanísticos de infraestrutura e renovação de áreas degradadas. A diferença fundamental de um circuito para outro reside na transformação do espaço urbano como valor-de-uso para valor-de-troca de acordo com Lefebvre (2008b) e Harvey (2011).

Marx em O Capital Vol. III tratou do conceito de valor a partir da fórmula trinitária (capital-lucro, terra-renda fundiária e trabalho-salário). Marx (1894/2017) argumenta que existe uma correlação entre as fontes de rendimento com o capital, o trabalho assalariado e a renda fundiária que se expressam como formas sociais historicamente determinadas e, portanto, fazem parte da formação econômica da sociedade. O autor analisa, portanto, a dinâmica do sistema capitalista como uma totalidade, na qual distingue as três dimensões da mercadoria: o valor de uso, o valor de troca e o valor. Importante notar que na época de suas formulações, a renda da terra era advinda do trabalho objetivado sobre ela, como na produção do trigo, por exemplo. Para a terra agrícola era conferido o valor-de-uso, enquanto que para o trigo, o valor-de-troca. Ou seja, a terra era o meio de produção e não produto do qual a mais-valia era extraída a partir da circulação da mercadoria.

No entanto, a questão da propriedade da terra foi fundamental para o regime de acumulação capitalista primitivo. Primeiro, pela espoliação dos camponeses forçando sua ida para as cidades em busca de meios para reproduzir sua vida, constituindo, assim, uma massa de trabalhadores que se submetem às condições de 
exploração mais vis sob a forma aparente da liberdade. Ao mesmo tempo, no campo, a terra se configura como propriedade imobiliária e também fonte de acumulação (não exclusivamente agrícola), muitas vezes pela exploração de camponeses com diferentes formas de dependência dos latifundiários. Esse duplo processo leva à intensa migração campo-cidade e rompe com relações sociais e modos de vida até então existentes.

As cidades passam, portanto, por uma imensa transformação. São implementados projetos de escala urbana que vão desde a provisão de infraestruturas para a circulação de bens e mercadorias (como as linhas férreas) até projetos de limpeza urbana (como áreas nas quais ocorre a demolição de moradias insalubres do proletariado) e de construção de habitações para a burguesia. Importante destacar que tanto os projetos de infraestrutura, quanto os projetos de transformação de áreas habitacionais e de embelezamento urbano, são organizados por empresários e industrialistas, com ligações entre eles e com o Estado. Em termos lefebvrianos, o espaço é tomado, pelas classes dominantes, como um instrumento para realizar ações que, sob o pretexto de representar os interesses de todos e higienizar áreas da cidade, de fato, expressam práticas de higienização social, precursores do que Smith (2006) viria a definir como gentrificação com a destruição de áreas inteiras de moradias proletárias para realizar obras de infraestrutura, incorporá-las ao mercado imobiliário ou criar áreas de lazer para a burguesia. Portanto, no regime de acumulação a distribuição se dá de maneira desigual. $\mathrm{Na}$ definição de Smith (2006), os processos de gentrificação não envolvem apenas mudança social, mas uma mudança física que combina a higienização social com a reabilitação das áreas para que utilização por estratos sociais com maior poder de compra que os moradores originários.

Assim, com a consolidação do capitalismo, a terra urbana passa a ser instrumento para o exercício do poder das classes dominantes sob a égide da acumulação e com a marca da higienização social. Harvey (2012) reconhece o papel da urbanização na história de acumulação do capital, mencionando especificamente o uso do capital excedente para construir as cidades, ao constatar que a crise do capital que se expressou na dos anos 1930, foi resolvida, nos Estados Unidos, em meados dos anos 1940, pelo incremento de projetos de suburbanização.
Lefebvre (1972/2008b) ao tratar da produção do espaço urbano (composta pela tríade do vividoconcebido-percebido) identifica o espaço não apenas como o meio para a produção capitalista, ou seja, a cidade enquanto valor-de-uso, como ambiente construído para a moradia dos trabalhadores e construção das fábricas e infraestruturas que viabilizam a produção de manufatureira; mas como a própria mercadoria na qual o espaço urbano detém também um valor-de-troca, assim como tem o trigo. No entanto, o espaço para Lefebvre, não é nem meio, nem fim, ainda que seja um instrumento político intencionalmente manipulado por um indivíduo ou um coletivo que detém poder sobre ele, e que o transforma conforme seus objetivos.

Para Lefebvre "as cidades seriam tão somente unidades de consumo correlatas às grandes unidades de produção" (1972/2008b, p. 46). A essa formulação se incorpora a teoria da alienação: o espaço instrumental se torna abstrato a partir de uma falsa representação de vocação estratégica, passando a ser "um lugar fora do tempo, da vida e da práxis". O espaço assume a forma de mercadoria, em que, "no limite [,] não há mais exatamente ideologia, mas somente a falsa consciência, com os discursos que ela engendra". Assim, aqui se retoma a noção de espaço absoluto - o espaço como mediação, o espaço instrumental, ou, em outros termos, expressão prático operacional de uma ideologia.

Entretanto, o autor alerta que essa hipótese servia ao capitalismo concorrencial do século XIX, cujo enfoque recaia na reprodução dos meios de produção. Ao se renovar, o capitalismo incorporou a "reprodução das relações de produção" que se efetuam através da cotidianidade e dos momentos de lazer e cultura. Essa noção é complementar à última hipótese apresentada, mas leva a outra, mais complexa: "o espaço estaria essencialmente ligado à reprodução das relações (sociais) de produção" Lefebvre (1972/2008b, p. 48).

Retoma-se, nesse ponto, a já citada noção de Harvey (2011) sobre a sedução pelo embelezamento e os símbolos de distinção social. Espaços homogêneos, com uma estética específica, criados em recortes em partes fragmentadas no tecido urbano, tornam-se centros ou subcentros de consumo, polos de atração de uma determinada classe social, causando estranheza e constrangimento aos demais e interferindo diretamente 
no poder do espaço, assim como na dinâmica da estrutura urbana. Segundo Lefebvre (2008a), tais centros de consumo dirigido e organizado - os lugares de lazer, de festa e tempo livre - mostram-se aparentemente dissociados da produção, embora estejam ligados ao trabalho produtivo na sociedade burocrática do consumo organizado.

Harvey (2006) define, também, as práticas de empreendedorismo urbano que ganham um papel central na produção das cidades a partir dos anos 1980. O governo empreendedor, denominado por Osborne \& Gaebler (1993), o marketing urbano, por Kotler, Haider e Rein (1994), e a cidade como máquina de crescimento, por Logan e Molotch (1993), são abordagens centrais para a sua formulação. Segundo Harvey (1989/2006), o empreendedorismo urbano tem como um de seus elementos básicos as parcerias público-privadas (PPPs) ${ }^{1}$, nas quais o governo local se alia a empresas privadas com a finalidade de angariar investimentos para a construção de projetos, ou mesmo, a manutenção de estruturas e espaços. Além disso, Harvey (1989/2006, p. 171) afirma que a PPP é empreendedora e especulativa, ou seja, "sujeita a todos os obstáculos e riscos associados ao desenvolvimento especulativo, ao contrário do desenvolvimento racionalmente planejado e coordenado". No entanto, é usual que os riscos incorram apenas para o setor público e os lucros para o privado. Harvey (1989/2006) afirma, ainda, que o empreendedorismo enfoca muito mais na economia política do lugar do que no território, referindo-se a que a construção de um lugar pode gerar impactos além de seu território específico e mudar a imagem da cidade mundialmente.

Esta característica empreendedora e especulativa não se limita, no entanto, sob as formas de agir dobre o espaço urbano. Harvey (2011) no mesmo ano, aponta para uma série de experimentações e inovações em diferentes setores da sociedade, sejam estes políticos, econômicos ou sociais, que veem a estabelecer um novo regime de acumulação, denominado por Harvey (2011) como regime de acumulação flexível, baseado na flexibilização de produção e consumo, caracterizado pela inovação nos

\footnotetext{
${ }^{1}$ No Brasil a parceria público-privada (PPP) é um termo jurídico para um
} modelo de negócio envolvendo o setor público e o setor privado. setores de produção, serviços financeiros e novos mercados, mas, acima de tudo, inovação comercial, tecnológica e organizacional. Neste cenário, segundo Harvey:

O mundo das altas finanças compreende uma variedade igualmente desconcertante de atividades transversais, nas quais os bancos tomam dinheiro emprestado de outros bancos, companhias de seguros e fundos de pensão formam conjuntos tão vastos de fundos de investimento que funcionam como criadores de mercado dominantes, enquanto comerciantes industriais, e o capital fixo tornou-se tão integrado às operações e estruturas financeiras que se torna cada vez mais difícil dizer onde começam os interesses comerciais e industriais e os interesses estritamente financeiros terminam. (2011, p. 161)

Assim como Harvey, outros autores definem esta nova fase do capitalismo como regime de acumulação financeira (Chenais, 1997), por exemplo. Já Krippner (2005) define o fenômeno da financeirização como um padrão de acumulação no qual a obtenção de lucro ocorre cada vez mais através de canais financeiros e, não, através da produção e comércio de mercadorias. No entanto, o mercado financeiro não se constitui apenas através da forma Dinheiro-Dinheiro (D-D) (Marx, Livro III), no qual o início e o fim da produção se efetuam exclusivamente da forma dinheiro (juros, renda), mas desta inter-relação entre as diferentes atividades comerciais incluindo o espaço urbano enquanto meio material da acumulação flexível.

Para Gotham (2009), a partir da experiência dos Estados Unidos, a relação entre o espaço urbano construído e o mercado financeiro ocorreu pelo processo de securitização, principalmente no que diz respeito ao setor habitacional. Segundo Sandroni (1999) o verbete securitização:

significa o processo de transformação de uma dívida com determinado credor em dívida com compradores de títulos originados no montante dessa dívida. Na realidade, trata-se da conversão

Entretanto, Harvey (2006) se refere a parcerias em prol de um objetivo em comum, seja ela formal ou informal. 
de empréstimos bancários e outros ativos em títulos (securities) para a venda a investidores que passam a ser os novos credores dessa dívida. ( $p$. 548)

Segundo Gothan (2009), um ativo imobiliário se define por sua rigidez espacial baixa liquidez, ou até mesmo sem liquidez, ou seja, é um capital fixo. Mas a rigidez espacial não limita a migração de um ativo ilíquido para um ativo líquido, no qual seja fácil a sua percepção de valor. Este fenômeno diz respeito à criação de valor de um ativo via influência de agentes externos via marketing e empreendedorismo urbano, por exemplo. Nesse sentido, a liquidez de um ativo imobiliário vai depender diretamente da paisagem e infraestrutura urbana no qual ele está contido, mas também das relações sociais de produção que se estabelecem. Por exemplo, as ações institucionais e legais por parte do estado e atores políticos envolvidos, dos movimentos sociais que atuam naquele espaço em específico. Segundo Gotham:

O sistema financeiro e o processo de financeirização se inter-relacionam com o estado por meio de políticas econômicas e regulatórias que impactam os mercados habitacionais e buscam promover a liquidez nos setores imobiliário residencial, comercial e industrial. O Estado desempenha um papel fundamental na dialética da rigidez espacial e da liquidez através de uma variedade de políticas, ações legais-regulatórias e investimentos em infraestrutura que podem reforçar a coerência territorial e promover fluxos entre cidades e regiões. (2009, p. 360)

Na passagem acima, Gotham (2009) alerta não apenas para as relações sob o espaço urbano, mas para a flexibilização e regulamentação de novas formas de interrelação entre o mercado financeiro e o imobiliário. De tal maneira, é possível compreender a financeirização à luz da tríade da produção do espaço urbano global.

\section{Metodologia}

A estratégia de pesquisa adotada é de um estudo de caso, a partir de projetos desenvolvidos ao longo da Orla de Porto Alegre, capital do Estado do Rio Grande do Sul (RS). A cidade é conhecida internacionalmente, pela experiência pioneira do Orçamento Participativo, por ter sido sede de edições do Fórum Social Mundial, da Bienal do Mercosul e da Copa do Mundo 2014.

Stake (1995) identifica três tipos de estudos de caso: (1) intrínseco - busca o melhor entendimento de um caso particular; (2) instrumental - um caso particular é examinado principalmente em busca de informações sobre o tema, o caso é de interesse secundário e tem um papel de suporte; (3) coletivo - é um estudo instrumental ampliado para múltiplos casos. Esse é um estudo de caso instrumental, já que a presente pesquisa tem como perspectiva contribuir, a partir do caso de Porto Alegre, para compreender as transformações contemporâneas relativas à produção do espaço urbano e à financeirização no Brasil e América Latina, especificamente, em áreas urbanas que tem o fator locacional de interface com as águas.

Realizou-se um estudo de caso único, com duas unidades de análise incorporada que por sua vez, contiveram subunidades. As unidades de análise (1) cidade empreendedora e (2) cidade financeirizada $e$ inovadora contêm projetos em diferentes estágios de andamento, seja em execução, licenciamento, planejamento ou capitalização. Para a unidade de análise cidade empreendedora são destacados os seguintes projetos: Parque Moacyr Scliar, Cais Mauá e Beira Rio. Para a unidade cidade financeirizada e inovadora são destacados: Cais Mauá (nova fase), Passeio Joquei, Pontal de Estaleiro e Porto Alegre 4D. Além destes projetos, na conclusão dois projetos são lembrados, mas ainda não desenvolvidos por estar em fase muito inicial, no entanto, já apresentam forte resistência da população. Ambos localizados na orla extremo-sul da cidade e em áreas de preservação ambiental: (1) Condomínio de luxo Preserva do Arado - 2.300 unidades habitacionais e hotel; e (2) Loteamento Ipanema - área de $70.641 \mathrm{~m}^{2}$.

O estudo se posiciona no campo dos Estudos Críticos Urbanos (Brenner, Marcuse, \& Mayer, 2012) e tem como repertório fundamental a obra de Henri Lefebvre. A análise dos dados se dá a partir dos conceitos de espaço e sua relação com a totalidade da sociedade capitalista, das possibilidades associadas à realidade urbana e do movimento de alienação-deselienação-realienação (Lefebvre, 2014). Estes conceitos subsidiam a tríade da produção do espaço (Lefebvre, 1991) que compreende um movimento trialético entre o espaço concebido (dos 
técnicos, arquitetos e urbanistas), o espaço percebido (a prática espacial), com o espaço vivido (os espaços de dominação e/ou de transformação).

A seguir serão apresentados os resultados a partir dos dados coletados a partir de reportagens de jornais e revistas, propaganda do setor imobiliário, sites oficiais das empresas e sites oficiais de operadoras de Fundos Imobiliários, entrevistas e observação participante.

\section{Resultados}

Desde os anos 1980, foram realizadas inúmeras tentativas de Grandes Projetos Urbanos (GPUs) para transformação da Orla do Guaíba e do Cais Mauá, a exemplo de Inner Harbour, Port Vell, Puerto Madero e London Docklands. A partir da realização da Copa do Mundo de 2014 em Porto Alegre, estas propostas se consolidaram sob um terreno fértil de oportunidades de investimentos. Nas partes que seguem apresentados os resultados das duas unidades de análise: cidade empreendedora e cidade financeirizada e inovadora.

\section{Porto Alegre: cidade empreendedora}

Nos últimos dez anos, a cidade passou por importantes alterações, sendo as mais evidentes a construção de avenidas perimetrais e a verticalização das edificações nas áreas próximas a elas. Além disto, Porto Alegre ganhou destaque internacional com o Museu Iberê Camargo, concluído em 2008. O projeto, do arquiteto português Álvaro Siza ganhou o Leão de Ouro na Bienal de Arquitetura de Veneza, em 2002, e representa uma edificação-ícone no skyline da cidade. Também em 2008 foi inaugurado o Barra Shopping Sul, localizado a poucos metros do Museu, e conta com um complexo de torres residenciais e de escritório ainda em fase de conclusão.

Outro momento marcante que coloca a capital no cenário internacional como cidade empreendedora e competitiva foi a realização da Copa do Mundo de 2014. Aprovada cidade-sede em 2009, o prefeito em parceria com o setor privado elaborou uma série de GPUs (quatorze de mobilidade urbana, dois estádios de futebol e dois projetos às margens do Rio Guaíba). Dos quatorze projetos de mobilidade urbana, cinco representam o incremento de A Figura 1 apresenta a localização dos GPUs.

Para o GPU Complexo Beira-Rio (estádio sede do megaevento) foram aprovadas importantes alterações de zoneamento e de índices: permissão para a construção de edificações mais altas (de 18 para $33 \mathrm{~m}$ ) e com índices construtivos superiores (1,3 para 1,9); a faixa da APP que era de pelo menos $500 \mathrm{~m}$ a partir dos cursos das águas foi reduzida para 255. Além dos parâmetros urbanísticos, isenções de impostos foram concedidas. Do projeto completo (reforma do estádio, $5 \mathrm{mil}$ vagas de estacionamento, centro de convenções, hotel 5 estrelas, centro de medicina esportiva, prédios comerciais e a recuperação da Orla do Guaíba), apenas o Estádio de Futebol e as vagas de estacionamento foram concluídos. Ainda assim, a duplicação das avenidas do seu entorno foi realizada com dinheiro público e moradores da Ocupação 20 de Novembro e galpões de escolas de samba foram removidos para dar lugar a um grande terreno vazio.

Atualmente foram retomadas as tratativas para a construção de um centro de medicina esportiva, hotel e centro de eventos da cidade. Embora o Clube de Futebol já tenha adquirido a flexibilização dos parâmetros urbanísticos para executar o empreendimento tal qual havia sido concebido, nesta nova etapa, novas flexibilizações estão sendo solicitadas. $O$ atual projeto das duas torres pretende abrigar, além do programa acima descrito, imóveis para moradia e serviços. Além da flexibilização de usos e exploração comercial de um terreno doado pelo Município para fins de uso esportivo, exclusivamente, uma das torres será a mais alta do estado, uma vez aprovado. O caso é um exemplar de planejamento de facilitação (Brindley, Rydin, \& Stoker, 2004), com o poder público participando ativamente da resolução do problema da sobreacumulação em processos de renovação urbana que incluem a exploração de terras desvalorizadas, a expulsão dos mais pobres, a desconsideração dos aspectos ambientais e a gentrificação, além do investimento de recursos próprios em benefício do empreendedor. 


\section{Figura 1}

Projetos urbanos e empreendimentos imobiliários em Porto Alegre

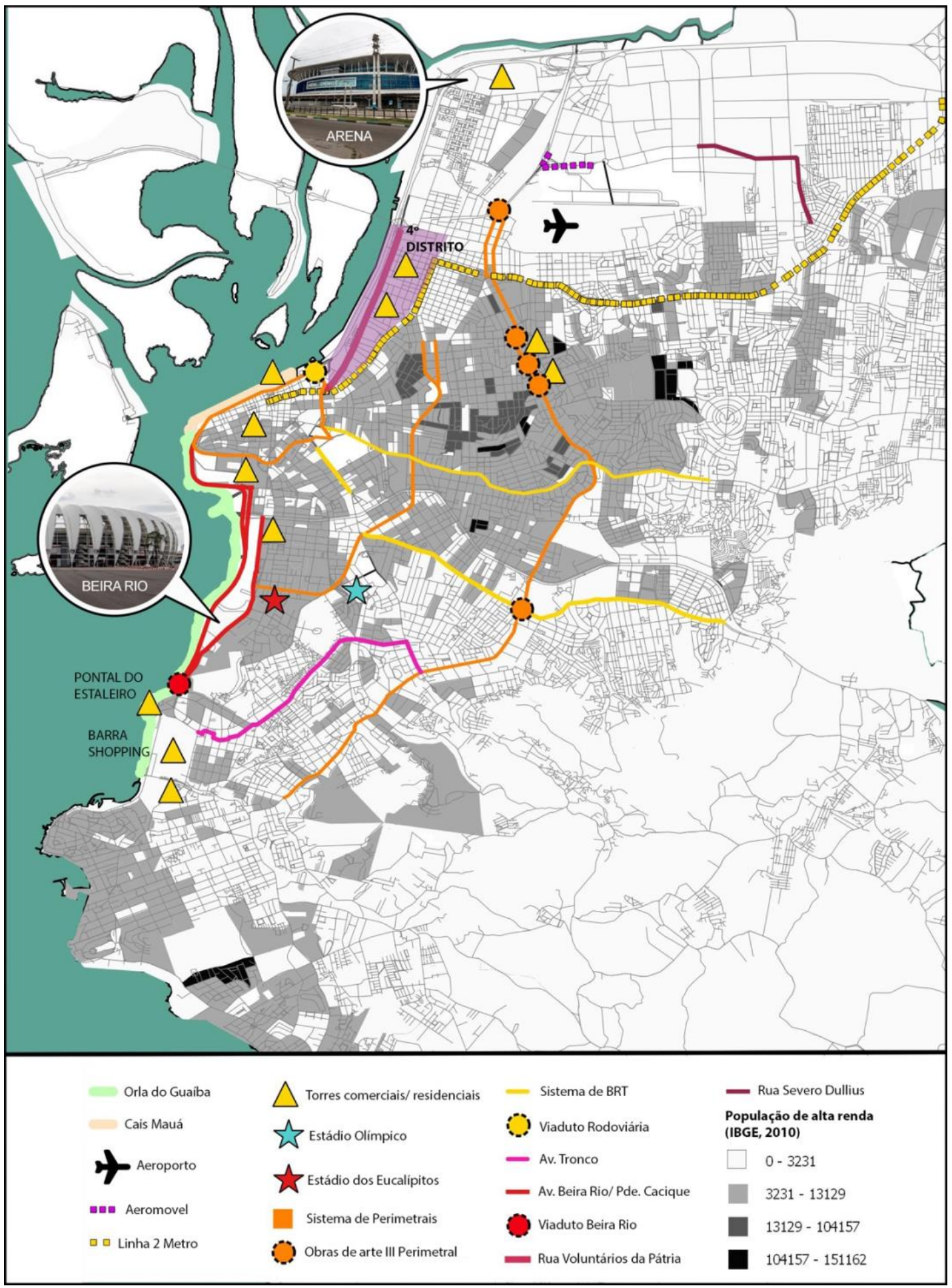

Fonte: Elaboração minha 
Já o projeto do Parque Moacyr Scliar (Orla do Guaíba), era visto de forma integrada com o Cais Mauá e, igualmente, importante para a Copa do Mundo: "A implantação do projeto de revitalização irá transformar esse espaço nobre da cidade, resgatando o convívio da população com o Guaíba, disse o Prefeito, lembrando que a qualificação estará associada ao empreendimento da Revitalização do Cais Mauá" (Gabinete de Comunicação Social, 2012).

O Instituto dos Arquitetos do Brasil (IAB) do Rio Grande do Sul solicitou a realização de audiência pública para que o arquiteto Lerner pudesse explicar o projeto à sociedade. $\mathrm{Na}$ ocasião, representantes de entidades e movimentos sociais e vereadores expuseram os seguintes pontos: contratação de Jaime Lerner por $\mathrm{R} \$$ 2,15 milhões sem a realização de concurso público de projeto; exclusão de técnicos da SPM e da população em geral; ausência de Estudo de Impacto Ambiental (EIA-RIMA). Devido à forma como o processo foi conduzido, muitos alertaram na época para o caráter elitista que se configuraria a partir do GPU. Este trecho da Orla é um importante espaço de lazer para moradores da cidade e da região metropolitana.

Poucos meses após a inauguração do parque, foi possível constatar que a previsão se concretizou. A Guarda Municipal expulsa moradores de rua e pessoas pobres, além de autuar vendedores ambulantes, agora proibidos de trabalhar no local. O comercio de alimentos e bebidas se dá por restaurantes previstos no projeto e por foodtrucks. Os banheiros públicos estão fechados e o almoço custa $\mathrm{R} \$ 50,00$, por um prato feito.

A contratação de Lerner se relaciona com o que Harvey (2011) chama de espetáculo urbano, referindo-se à fetichização do espaço via design de arquitetos de renome. O GPU da Orla do Guaíba recebeu investimentos do Ministério do Turismo. Em 2015 foi assinado o investimento do Banco de Desenvolvimento da América Latina - o CAF (Corporação Andina de Fomento), instituição internacional multilateral que financia projetos de desenvolvimento na América Latina. Atualmente a PMPA concedeu o espaço à iniciativa privada em troca de sua manutenção. Uber é a empresa responsável.

Já para viabilizar o Cais Mauá, foi alterada a legislação para autorizar novos usos e concedidos índices construtivos atraentes para a construção civil. Após, foi aberta a licitação da qual saiu vencedora a empresa
Consórcio Cais Mauá (liderada pelo grupo espanhol responsável pelo Port Vell, em Barcelona, e integrado pelo arquiteto Jaime Lerner), que teria o direito de exploração da área por 25 anos. O GPU Cais Mauá é um exemplo das alianças formadas entre as diferentes esferas de governo para tornar o projeto atrativo para o mercado.

Na coalizão para a implantação de GPUs sob a ótica do empreendedorismo urbano, o Grupo RBS mais uma vez atuou com força. Em reportagem especial afirmou que o Cais Mauá “(...) será palco hoje de uma espécie de renascimento da metrópole", acrescentando: "ao meiodia, o Governador Tarso Genro transfere a posse dos mais de 180 mil metros quadrados do Cais Mauá à iniciativa privada, o sonho de que aquele se torne um lugar realmente público começa a virar realidade" (Melo, 2011). Observa-se uma inversão de termos e uma retórica mistificadora. O local, que até então abrigava diversas atividades efêmeras de caráter aberto e público, além de atividades permanentes como marina pública, vai se tornar "um lugar verdadeiramente público" ao ser entregue para o setor privado? No que se refere aos impactos na região central da cidade, além de aumentar o fluxo de automóveis e pessoas de alta renda que consumirão os produtos oferecidos no empreendimento Cais Mauá, ao que tudo indica, ocorrerá junto o fenômeno da gentrificação. Mais sobre o GPU Cais Mauá será tratado a seguir.

A partir destas três subunidades, é possível constatar que sediar o megaevento foi estratégico para acessar recursos internacionais e difundir a imagem de uma cidade moderna, desenvolvida e eficiente, seguindo a lógica da concorrência interurbana em uma nova geografia de centralidades periféricas. Além disso, a escolha e a gestão dos projetos se articulam sempre com temas relacionado ao crescimento econômico, ao empreendedorismo e à criação de um ambiente favorável aos negócios, todos considerados positivos segundo a lógica do empreendedorismo. Nesse contexto se aprofundam as práticas gerencialistas, de modo coerente com a dimensão cultural do empresariamento.

Para os GPUs vinculados à Copa do Mundo, foram constatadas a aplicação de três das quatro estratégias de empreendedorismo urbano definidas por Harvey (1989/2006). São elas: divisão espacial do consumo, das atividades de controle e comando, redistribuição de 
superávits do governo, sendo que quase todas se basearam em parcerias público-privadas (PPP). Tais práticas se associam à utilização de um planejamento de tendência (Brindley, Rydin e Stoker, 2004) que reorienta o planejamento de interesse público para atender interesses privados e implementam processos de acumulação por espoliação (Harvey, 2012), preparando uma área com potencial de mercado para a intervenção das empresas de construção uma vez livre da cidade informal. Esse tipo de planejamento abandona a própria razão de ser do planejamento - entendido como a concepção de caminhos para um futuro desejado -, transformando-o em mero espaço de interlocução entre agentes públicos e parceiros privados selecionados e resultando em ações pontuais ditadas por interesses também pontuais.

Por fim, a realização do megaevento em Porto Alegre, estimulou a compressão espaço-tempo no processo de produção do espaço urbano, uma vez que o megaevento teve uma data determinada para acontecer. Esta compressão de cunho neoliberal alterou as formas de organização vigentes até então. Cabe destacar que, principalmente na década de 1990 , movimentos sociais e os moradores de Porto Alegre haviam vivenciado processos participativos e inclusivos. A realização do megaevento configura, portanto, não apenas a oportunidade de investimentos estatais e estrangeiros, mas sobretudo, a oportunidade de transformação das relações sociais de produção até outrora vigentes.

\section{Porto Alegre: cidade financeirizada e inovadora}

Passada a Copa do Mundo de 2014, passou também o sentimento de bem-estar associado aos jogos (Maennig, 2009). Ainda antes da realização do megaevento, movimentos sociais como o Movimento em Defesa Publica da Alegria realizou diversas atividades na área do Cais reivindicando a privatização de uma área pública e o consequente cerceamento de atividades que eram realizadas periodicamente no local. Seguindo a linha dos movimentos Ocuppy, as ações do Movimento em Defesa Publica da Alegria deram origem a outro movimento, o Ocupa Cais Mauá, que promove eventos envolvendo manifestações artísticas e culturais além de festas. O movimento se transformou posteriormente no Cais Mauá de Todos que atualmente é uma associação, o AMACAIS, e reivindica o descaso com o patrimônio histórico, o desrespeito com o meio ambiente e a maneira autoritária na qual vem sendo realizado o processo de transformação do porto.

Entre o final de 2014 e o início de 2015, o processo de implemente ação do GPU ganha novos contornos. O grupo espanhol saiu do Consórcio Cais Mauá e Jaime Lerner passou a ser o arquiteto responsável. Um novo consórcio foi criado, o Consórcio Viva Cais Mauá. Importante destacar que este GPU corresponde a uma prática de planejamento de administração privada (Brindley, Rydin e Stoker, 2004), pois o Consórcio escolhido é o responsável pelo planejamento, gestão e exploração do espaço por 25 anos.

Em 2016, o IAB-RS entrou com uma ação civil pública contra o Consórcio, alegando uma série de irregularidades no processo. Uma delas seria o vencimento da lei que altera os parâmetros urbanísticos, uma vez que, caso as obras de instalação não ocorressem até dezembro de 2012, a lei caducaria. Outra questão é a falta de comprovação dos aportes financeiros necessário ( $R \$ 400$ milhões) para participar do processo licitatório que definiria o consórcio vencedor (Gomes, 2016).

Em 2018, com o projeto ainda não iniciado, a Polícia Federal deflagrou uma operação envolvendo fraudes nos fundos de investimento do GPU Cais Mauá, pois o dinheiro dos fundos de pensão era aplicado pelo Consórcio sem que as obras tenham começado. A empresa ICLA Trust Serviços Financeiros era a responsável pelos investimentos da obra, que em 2017 deixou de integrar o Fundo de Investimentos em Participações Cais Mauá do Brasil (PF..., 2018). Um dia após a deflagração da operação, a Reag Adminsitradora de Recursos Ltda, administradora do Fundo de Investimento em Participações Cais Mauá do Brasil Infraestrutra desde fevereiro de 2018, declara o fechamento do Fundo para a realização de novas aplicações seja por novos investidores, seja pelos seus atuais cotistas.

A Reag Investimentos é uma plataforma de negócios independente que desenvolve soluções financeiras customizadas. Dispõe de um amplo portfólio de produtos e serviços financeiros que, integrados, permitem atender às particularidades de cada segmento de clientes, considerando diferentes objetivos e perfis de risco. As soluções financeiras são estruturadas em sete áreas de negócios, sendo elas empresas de gestão de recursos, 
securitização e administração de créditos, mercado de capitais, representação e desenvolvimento imobiliário, assessoria financeira, vendas e distribuição. A empresa [...] lidera, desde 2014, o ranking da Uqbar/Tlon de Estruturadores de Fundos de Investimento Imobiliário (FII) (Dorneles, 2018).

Os Fundos de Investimento Imobiliário citados na passagem acima podem ser classificados da seguinte forma: (1) Fundo de Renda ou Fundos de Tijolos, no qual o investimento é realizado na construção de imóveis para alugar, como em shopping centers, galpões industriais, imóveis residenciais e hotéis; (2) Fundo de Desenvolvimento; fundo que investe na construção de um imóvel para venda, o risco neste caso recai sob o investidor e não sob o incorporador; (3) Fundo de Compra e Venda; investe na compra de imóveis em baixa e venda dos mesmos em períodos de aquecimento do mercado imobiliário ou em regiões valorizadas; (4) Fundo de Recebíveis Imobiliários ou Fundos de Papel, são títulos de renda fixa usados para a captação de recursos para investir no mercado imobiliário; (5) Fundo dos Fundos, no qual se investe em uma carteira diversificada de Fundos Imobiliários.

O Consórcio Cais Mauá recorreu a esta forma combinada de investimento para capitalizar o consórcio para a realização do projeto. Modelo de negócio que uma vez construído ainda poderá ser recolocado no mercado financeiro via Fundo de Renda. Mas o mais importante a destacar aqui, é que ter um projeto urbano em mãos viabiliza a abertura para o mercado financeiro, mesmo que o projeto jamais venha a ser construído, como parece ser o destino do Cais Mauá.

Outros projetos mais associados ao mercado imobiliário como condomínios fechados também recorrem a esta combinação com os fundos de investimento. Os projetos Passeio Joquei Residencial e Estaleiro Só são um exemplo disto.

O projeto Passeio Jóquei Residencial pertence à Multiplan, empresa responsável pela construção do Barra Shopping Sul mencionado anteriormente. Em 2006 a empresa fez uma parceria com o Ontario Teachers' Pension Plan (OTPP), fundo de pensão de professores canadenses. Em 2007 empresa realiza o IPO (Initial Public Offering) na Bolsa de Valores. Em 2015 as ações da Multiplan (MULT3.SA) passam a fazer parte do principal índice da Ibovespa, a Bolsa de Valores de São Paulo. Além disso, as participações dos shoppings da Multiplan são compartilhadas com Fundos de Previdência como a Fundação Sistel de Securidade Social (Fundo de Previdência do sistema Telebrás), Previ (Fundo de Previdência dos funcionários do Banco do Brasil), Fapes (Fundo de Previdência dos funcionários do Banco Nacional de Desenvolvimento - BNDES) e Funcef (Fundo de Previdência dos funcionários da Caixa Econômica Federal).

Importante destacar na área do atualmente construído Barra Shopping Sul e do futuro Passeio Jóquei Residencial era ocupada por favelas que se distribuíam ao longo da avenida e do arroio que divide as duas áreas. As famílias foram realocadas no extremo sul da cidade.

O projeto Pontal do Estaleiro é outro que passou por diferentes momentos até receber as permissões para a construção. Em 2003 a BM Par Empreendimentos adquiriu a área onde funcionava o Estaleiro Só. Foi elaborado, então, um projeto que previa a transformação da área em um condomínio fechado de torres residenciais, mas para colocar em prática conforme planejado era necessária a alteração do Plano Diretor da cidade. Diversos movimentos sociais e ambientalistas formaram uma ampla resistência ao projeto, que culminou em 2009 com uma consulta pública, na qual $80 \%$ disseram não ao uso residencial para a área localizada ao lado do Museu Iberê Camargo.

Um novo projeto foi desenvolvido e com as devidas permissões para a sua construção foi lançado para a sociedade em evento no ano de 2018. Na ocasião o, então Prefeito Nelson Marchezan crítica o processo que barrou o empreendimento no passado:

meia dúzia de pessoas tiveram espaço para debater por anos, com os argumentos mais irracionais. $E$ receberam o mesmo espaço do que interessa, que é recuperar a orla. Foram os mesmos argumentos irracionais contra o Cais, licenciado no ano passado após 30 anos de discussão. (Kolling, 2018)

O Prefeito foi aplaudido por corretores imobiliários (Kolling, 2018).

Já para Leandro Melnick, Presidente da Melnick Even construtora responsável pelo empreendimento, 
Como um Porto Alegrense que não tivesse nenhuma relação com este empreendimento eu estaria emocionado, a ver que a nossa cidade vai finalmente ter uma relação real e forte, publica, aberta com o Rio Guaíba. [...] Uma relação que eu acho que sonhada a muito tempo começou a se materializar nesta região com o Barra, o Iberê, as obras da Copa, recente com na revitalização da orla. E agora com este equipamento tão completo, ele vai realmente trazer de novo para o cidadão de Porto Alegre, para nossa população, o convívio com o Rio Guaíba. (Kolling, 2018)

Percebe-se que o projeto atual se difere do projeto anterior, pois compreende o uso de salas comerciais, shopping center, hotel cinco estrelas da Double Tree by Hilton, Centro Médico e a doação de área pública ao longo de $700 \mathrm{~m}$ de orla. Desde o lançamento do empreendimento, a fim conquistar o consenso da sociedade porto-alegrense sobre o projeto, os empreendedores abriram ao público uma pequena fração do parque com praça infantil e foodtruck, tal qual esta previsto para o parque quando concluído. Embora não se trate de um condomínio fechado, ao que tudo indica, não se tratará de uma área amplamente pública, a exemplo do Parque Moacyr Scliar.

A venda do empreendimento é de responsabilidade da Bridge Companhia Imobiliária, que vai desde cotas para investidores no Hotel como também a oferta de compromisso de compra do imóvel do atual comprador após a conclusão do empreendimento, além de oferta de linhas de crédito para a compra do imóvel. Especula-se a relação do empreendimento com FII.

Já o projeto Porto Alegre 4D se trata de um modelo de financeirização que dialoga diretamente com a mudança regulatória expressa no Estatuto da Cidade a partir de uma Operação Urbana Consorciada (OUC). Concomitante a realização da Copa do Mundo a PMPA começou a desenvolver o estudo para um projeto de revitalização de uma antiga zona industrial da cidade com o intuito em reconvertê-la em um distrito de inovação à exemplo do projeto @22Barcelona. É importante destacar que esta inciativa coloca em marcha a única estratégia de empreendedorismo urbano não empregada pela PMPA no período relacionado ao megaevento, a que se refere à criação de ambientes para a "exploração de vantagens específicas para a produção de bens e serviços" (Harvey, 2006, p. 172). Para isso, o poder público, usualmente representado por uma coalizão entre poderes municipais, estaduais e federais, estimula o investimento do setor privado por meio de redução de subsídios, como renúncias fiscais, doação de recursos etc. A concorrência internacional para localização de indústrias e empresas também depende não somente do custo da mão-de-obra, mas de uma força de trabalho habilitada e treinada a lidar com novas tecnologias. Nesse quadro, os investimentos em educação e tecnologia se tornam centrais.

É importante notar que o texto original escrito por Harvey é do final da década de 1980 e, mesmo que a prática deste referencial no Brasil ainda seja recente, ela já se apresenta com uma nova roupagem - o ideário das cidades criativas. Este referencial tem como objetivo retomar a posição das cidades como lócus privilegiado da produção após o fenômeno da desindustrialização em áreas urbanas. Segundo Laundry (2013), a cidade teria um papel central, pois nela se localizam os recursos imprescindíveis para esta reestruturação: as pessoas. Pessoas capacitadas com alto nível de instrução associadas a práticas de economia criativa e atividades como Living Labs contribuiriam para, por exemplo, resolver os problemas que a gestão urbana não consegue mais dar conta devido à complexidade das grandes cidades. Nesse cenário, a associação da tecnologia e da inovação para resolver os problemas da vida cotidiana nas cidades configuram as chamadas Smart Cities. Uma cidade criativa seria, portanto, além do lócus da matéria prima, a motivação para a criação da própria mercadoria.

O projeto que tem como lema transformar o 4음 Distrito no lugar mais inovador da América Latina começou a ser prospectado em meados de 2013, quando os empresários locais do grupo CITE (Cidadãos, Inovação, Tecnologia e Empreendedorismo) organizaram uma viagem ao Vale do Silício. Na ocasião foi uma comitiva de 30 pessoas incluindo o Prefeito de Porto Alegre José Fortunati, os secretários de Governança Local e de Planejamento e os coordenadorres do Gabinete de Inovação (Inovapoa) e de Gabinete Digital. Segundo o Prefeito

Porto Alegre é hoje, entre as 50 maiores cidades do Brasil, a segunda em criatividade e uma das que mais investe na indústria criativa e da inovação. Nós queremos consolidar a cidade como uma referência na área. $\mathrm{E}$ a ida 
ao Vale do Silício significa trazer investimentos, trazer mais esperança para o desenvolvimento desse importante setor para a nossa cidade. Sem contar que as novas tecnologias aprimoram a prestação de serviços e quem ganha com isso é a população, é o cidadão (Fernandes, 2013).

Diante desta questão, em 2015, uma comitiva composta pelo Prefeito e Secretários da PMPA e representantes do setor privado como da construção civil, educação e saúde fizeram viagem a Barcelona para conhecer a experiência do 22@Barcelona. Segundo o secretário municipal da Fazenda Jorge Tonetto, que coordena o grupo junto com o secretário de Urbanismo, Valter Nagelstein, "nesta primeira fase do projeto está sendo discutido todo o equipamento urbano necessário para dar uma ambiência de qualidade ao local e atrair investimentos de empresas" (Ferràz, 2015).

A mudança da coordenação do projeto para o Secretário da Fazenda Jorge Tonetto representa um marco no desenvolvimento do projeto. Segundo entrevistado, a Secretaria da Fazenda coordena o projeto pois é nela que se viabiliza economicamente a sua implementação. Ainda em julho de 2015 foram realizadas visitas técnicas em São Paulo e no Rio de Janeiro para conhecer as experiências das Operação Urbana Consorciada (OUC) do Porto Maravilha e da venda de Certificado de Potencial Adicional de Construção (CEPACS).

Tendo em vista a venda de CEPACs para a região e a possiblidade da emissão de debêntures da dívida pública, a PMPA aprovou na Câmara de Vereadores o projeto de Lei que cria a Empresa de Gestão de Ativos do Município S.A. InvestPOA, a exemplo de São Paulo e Belo Horizonte. Para a entrada da InvestePOA na bolsa de valores e a emissão de debêntures a PMPA colocou como garantia o seu patrimônio imobiliário. Esse processo de financeirização significa em ultima instancia a privatização de espaços públicos da cidade. Em 2015, o Ministério Público de Contas (MPC) e o Tribunal de Contas do Estado (TCE) pediram a suspensão da criação do InvestPOA, por irregularidades e risco ao erário.
Embora a venda de CEPACs pareça ser a fórmula para o sucesso de uma OUC, experiência como a do Porto Maravilha no Rio de Janeiro, demonstram que o setor privado não tem o interesse necessário para deslanchar uma operação deste porte. No caso do Rio de Janeiro, todos os CEPACs foram comprados pelo Funcef. No caso de Porto Alegre, segundo um dos entrevistados, mesmo com todo este aprimoramento nos instrumentos financeiros, a resposta do setor privado também não foi favorável ao investimento, não enquanto a área mantivesse suas características de degradação física e de vulnerabilidade social.

No segundo semestre de 2018 foi criada a Aliança para Inovação ${ }^{2}$ entre as principais Universidades da capital (UFRGS, PUCRS e UNISSINOS). O objetivo da Aliança é transformar Porto Alegre em uma referência de inovação, conhecimento e empreendedorismo, além do bem viver, enfocando na atração de talentos que tenham interesse em habitar em uma cidade como Porto Alegre. Nesse sentido, o Masterplan Porto Alegre 4D, projeto urbano desenvolvido por professor da Faculdade de Arquitetura da UFRGS, desempenha um papel fundamental, não apenas na orientação dos parâmetros urbanísticos e organização do ambiente construído para venda de CPACS, mas na orientação de uma paisagem urbana atrativa e higienizada.

No ano de 2018 o vice-prefeito municipal apresentou o Materplan em diversos eventos internacionais, em busca de investidores, o que incluiu o Banco Mundial, para o qual foi solicitado um financiamento de US\$ 160 milhões (Natusch, 2017). Recentemente uma comitiva formada pela PMPA e associados ao projeto estiveram em Washington para uma sucessão de reuniões como o Banco Interamericano de Desenvolvimento (BID). Como resultado, Porto Alegre terá acesso à recursos na ordem de US\$30 milhões para investimento no Porto Alegre 4D. O recurso será utilizado na melhoria de infraestrutura urbana da região e também na assessoria para a formação do Plano de Negócios, bem como, assistência técnica em formação de PPPs.

Importante destacar que o projeto foi elaborado sem

a participação da sociedade. Muitos são os

${ }^{2}$ Atualmente denominado Pacto Alegre. 
questionamentos sobre o projeto que é mantido à sete chaves, se não para grupos selecionados de investidores, donos de terrenos e comunidade acadêmica alinhada com o empreendedorismo e inovação. O GPU Porto Alegre 4D se estabelece com base no argumento de que a intervenção é necessária em uma área vazia que precisa ser revitalizada. Também apela para o passado histórico e o patrimônio arquitetônico da região. Mas, de fato o que representa são os interesses do mercado imobiliário, dos donos dos terrenos, das políticas públicas de empreendedorismo orientadas pela valorização e mercantilização do solo urbano. Assim, com uma estratégia midiática para uma área localizada entre o aeroporto, o Centro Histórico, a Orla do Guaíba e os bairros da elite, é produzida a crença de que a revitalização é boa e necessária para todos. Smith (2006) se refere à revitalização-renovação-regeneração urbana como um eufemismo alinhado à gentrificação generalizada e a uma estratégia de planejamento. 0 eufemismo reside em fazer crer que os espaços destinados a um determinado GPU não têm vida e, portanto, precisam ser revitalizados. Claro, no caso, 'ter vida' significa contribuir para processos cada vez mais intensivos de acumulação.

\section{Discussão}

É possível perceber que os projetos promovidos pelo estado se enquadram em estratégias de empreendedorismo urbano (Harvey, 2006) e buscam o marketing urbano e arquitetos de grife como marca da cidade (Álvaro Siza, Jaime Lerner e Fermin Vazques), mas, sobretudo, representa uma apropriação das margens da orla e de sua paisagem natural e histórica. A Orla do Guaíba é colocada como espaço instrumental do regime de acumulação imobiliário-financeiro.

Dos projetos analisados, Moacyr Scliar e Porto Alegre $4 \mathrm{D}$ recorrem a financiamentos de Bancos internacionais como o CAF e BID. Cais Mauá, Passeo Jóquei, Barra Shopping Sul e Pontal do Estaleiro tem suas práticas associadas a FII. Além disso, Cais Mauá, Pontal do Estaleiro, Porto Alegre 4D apresentaram forte resistência por parte da população e insurgências por determinados grupos contra os projetos. Este é o caso, também, de dois projetos ainda em fase o Loteamento Ipanema e o Condomínio Preserva do Arado. Ambos ainda sem aprovação da PMPA para o início das obras já sofrem forte pressão de moradores e ambientalistas. O caso da Preserva do Arado é mais significativo, pois uma tribo de índios Guarani ocupou a área, reivindicando como sua. Os proprietários das terras chegaram a fazer juras de morte à comunidade indígena que conta com o apoio dos moradores do bairro, entidades e movimentos sociais. Por fim, combinados, as Torres do Beira-Rio, o Barra Shopping Sul e o Passeo Joquei (localizados todos no Bairro Cristal e entorno imediato) representam a expulsão de moradores pobres na região e a extinção de antigos espaços públicos de lazer para os moradores do Complexo de Favelas Cruzeiro. Assim como Porto Alegre 4D representa a gentrificação eminente da região da Orla norte da cidade.

As novas relações que se desenvolvem a partir destes projetos em nada dialogam com a realidade urbana dos que ali habitam. $O$ incremento de infraestrutura com certeza é desejável por todos, desde que correspondam a uma melhoria da qualidade de vida justa e igualitária e não a privatização de espaços públicos para grupos específicos. Os movimentos sociais e moradores ao reivindicarem, algumas vezes com sucesso, exercem o movimento de desalienação. Estes acabam por ser caracterizados pela mídia como "carangueijos" contra o progresso e a modernidade. A equalização de forças entre o capital e as pessoas ilustra um campo de domínio sob os dominados, fato não considerado, sobretudo, imutável. A sociedade via resistência e a constante vigília sobre processos pouco participativos a respeito de interesses de grupos específicos configuram espaços representacionais de transformação e/ou dominação.

\section{Conclusões}

Percebe-se o espaço vivido que se coloca em contradição com o espaço concebido por uma coalisão para o crescimento (Logan e Molotch, 1993). O espaço concebido, que por sua vez, opera a partir da constante flexibilização de parâmentros urbanísticos, espoliação dos espaços públicos e estratégias de limpeza urbana a partir do desencadeamento de processos de gentrificação e até mesmo expulsão direta de moradores, confrontando diretamente a prática espacial (o espaço percebido), em termos Lefebvrianos.

Por fim, algumas considerações sobre a inovação, presente em diferentes esferas: (1) na transformados de espaços de lazer em espaços de consumo sob o falso 
manto do espaço público; (2) o mix de usos (hotéis, lojas, hospitais, centro de eventos) apresentados pelos empreendimentos de modo a fortalecer o portfólio de Fundos de Tijolos; (3) o uso de estratégias de marketing e urbanismo de experiência como espaço de dominação e alienação da sociedade para a formação de consenso sobre um projeto; (4) o uso da ideologia da inovação tecnológica em si como produtora de mercadoria urbana financeirizada; (5) a inter-relação entre o mercado financeiro e imobiliário nas novas formas de produzir a cidade; e (6) a formação de uma coalisão para o crescimento (Logan e Molotch, 1993) na sua plenitude, envolvendo estado, mídia, universidade e elite.

O caso de Porto Alegre ilustra, portanto, o aprofundamento das práticas neoliberais de governança empreendedora, em um primeiro momento, seguido de práticas que buscam a inovação tecnológica e inovação nas relações de produção, vinculadas ao regime de acumulação flexível [B]

\section{Referências}

Brenner, N., Marcuse, P., \& Mayer, M. (2012). Cities for people not for profit: an introduction. In Brenner, Marcuse, \& Mayer (org.), Cities for people not for profit: Critical urban theory and the right to the city, pp. 1-10. New York: Routledge.

Brindley, T., Rydin, Y., \& Stoker, G. (2004). Remaking planning: the politics of urban change. Nova York: Routledge.

Broudehoux A. (2016). Spectacular Beijing: The Conspicuous Construction of an Olympic Metropolis. Journal of Urban Affairs, 383-399 https://doi.org/10.1111/j.1467-9906.2007.00352.x

Chesnais, F. (2002). A teoria do regime de acumulação financeirizado: conteúdo, alcance e interrogações. Campinas: Economia e Sociedade, 11(18), 1-44. https://periodicos.sbu.unicamp.br/ojs/index.php/eco s/article/view/8643086

Dorneles, C. (27 de fevereiro de 2018). Jornal do Comércio. https://www.jornaldocomercio.com/ conteudo/2018 /02/economia/613425-cais-maua-agora-passa-a-seradministrado-pelo-grupo-reag.html

Ferràz, A. (22 de junho de 2015). Parques tecnológicos de Barcelona são modelo para o 4음 Distrito. Portal de Notícias PMPA.

http://www2.portoalegre.rs.gov.br/portal pmpa ser vidor/default.php?p noticia $=178597 \& P A R Q U E S+T E C$ NOLOGICOS+DE+BARCELONA+SAO+MODELO+PARA+ $\underline{\mathrm{O}+40+\mathrm{DISTRITO}}$
Fernandes, M. (21 de maio de 2013). Fortunati parte em missão oficial ao Vale do Silício. Notícias do Portal da PMPA. Recuperado de http://www2.portoalegre.rs.gov.br/portal pmpa nov o/default.php?p noticia=160745\&FORTUNATI+PARTE $+\mathrm{EM}+\mathrm{MISSAO}+\mathrm{OFICIAL+AO+VALE+DO+SILICIO}$

Gabinete de Comunicação Social - Prefeitura de Porto Alegre. (2018). Revitalização da Orla: últimos acertos antes da Licitação.

https://maispetropolis.wordpress.com/2012/10/18/r evitalizacao-da-orla-ultimos-acertos-antes-dalicitacao/

Gomes, L. E. (14 de março de 2016). Entidades apontam ilegalidades e pedem o rompimento do contrato de revitalização do Cais Mauá. Sul 21.

https://www.sul21.com.br/cidades/2016/03/entidad es-apontam-ilegalidades-e-pedem-o-rompimento-docontrato-de-revitalizacao-do-cais-maua/

Gotham, K. (2009). Creating liquidity out of spatial fixity: the secondary circuit of capital and the subprime mortgage crisis. International Journal of Urban and Regional Research, 3(2), 355-371. https://doi.org/10.1111/j.1468-2427.2009.00874.x

Hall, C. M. (2006). Urban Entrepreneurship, Corporate Interests and Sports Mega-Events: The Thin Policies of Competitiveness within the Hard Outcomes of Neoliberalism. The Sociological Review, 54(2), 5970. https://doi.org/10.1111/j.1467954X.2006.00653.x

Harvey, D. (2006). A produção capitalista do espaço. São Paulo: Annablume Editora.

Harvey, D. (2011). Condição Pós-Moderna: Uma pesquisa sobre as origens da mudança cultural. São Paulo: Edições Loyola. 
Harvey, D. (2012). O novo imperialismo. São Paulo: Edições Loyola.

KLAUSER, F.R. (2012), Interpretative Flexibility of the Event-City: Security, Branding and Urban Entrepreneurialism at the European Football Championships 2008. International Journal of Urban and Regional Research, 36, 1039-1052. https://doi.org/10.1111/j.1468-2427.2011.01064.x

Krippner, G. (2005). The financialization of the American economy. Socio-Economic Review, (3), 173-208.

Kolling, G. (13 junho de 2018). Obras do Pontal do Estaleiro devem ser entregues em 2021. Jornal do Comércio. Recuperado de: https://www.jornaldocomercio.com/ conteudo/econ omia/2018/06/632564-obras-pontal-devem-serentregues-em-2021.html

Kotler, P., Haider, D. H. e Rein, I. (1994). Marketing Público: Como atrair investimentos, empresas e turismo para as cidades, regiões, estados e países. São Paulo: Makron Books..

Laundry, C. (2013). Origens e futuros da cidade criativa. São Paulo: SESI-SP Editora.

Lefebvre, H. (1991) The production of space. Oxford: Blackwell.

Lefebvre, H. (2008a) Espaço e política. Belo Horizonte: Editora UFMG.

Lefebvre, H. (2008b). A revolução urbana. Belo Horizonte: Editora UFMG.

Lefebvre, H. (2014). Critique of everyday life. Vol I, II e III. London: Verso.

Logan, J. R., \& Molotch, H. L. (1993). The City as a Growth Machine. In, Fainstein, S. S., \& Campbell, S. Readings in Urban Theory. Oxford: Blackwells.

Maennig, W. (2009). World Cup 2010: South African economic perspectives and policy challenges informed by the experience of Germany 2006. Hamburg: Universität Hamburg.

McLeoad, G. (2002). From Urban Entrepreneurialism to a "Revanchist City"? On the Spatial Injustices of Glasgow's Renaissance. Antipode, 34, 602-624. https://doi.org/10.1111/1467-8330.00256
Marx, K. (2017). O Capital: crítica da economia política, Livro III: O processo global da produção capitalista. São Paulo: Boitempo.

Melo, I. (23 de nov. 2011). Pontapé inicial: Novo cais até a Copa. Zero Hora, 4-5.

Natusch, I. (2017). Banco Mundial é esperança para revitalizar o 4음 Distrito. Jornal do Comérico. Porto Alegre. Recuperado de: https://www.jornaldocomercio.com/ conteudo/2017 /12/geral/602647-banco-mundial-e-esperanca-pararevitalizar-o-4-distrito.html

Osborne, D \& Gaebler, T. (1993). Reinventing Government. How the entrepreneurial spirit is transforming the public sector. New York: Plume.

Owen, K. A. (2002). The Sydney 2000 Olympics and Urban Entrepreneurialism: Local Variations in Urban Governance. Australian Geographical Studies, (40), 323-336. https://doi.org/10.1111/1467-8470.00183

PF investiga fraudes em fundo de investimento que financiava obras de revitalização de Porto Alegre (19 de abril de 2018). Portal G1, Rio Grande do Sul. Recuperado de: (https://g1.globo.com/rs/rio-grandedo-sul/noticia/operacao-da-pf-do-rio-grande-do-sulcombate-fraudes-em-fundos-de-investimento.ghtml, acesso em 25 nov. 2018.

Smith, N. (2006). A gentrificação generalizada: de uma anomalia local à "regeneração" urbana como estratégia urbana global. In BIDOU-ZACHARIASEN, Catherine. (coord.) De volta à cidade: dos processos de gentrificação às políticas públicas de "revitalização" dos centros urbanos, pp. 59-87. São Paulo: Annablume Editora.

Stake, R. E. (1995). The art of case study research. London: Sage.

Tomlinson, R. (2010). Whose Accolades? An Alternative Perspective on Motivations for Hosting the Olympics. Urban Forum, 21(2), 139-152. https://doi.org/10.1007/s12132-010-9082-9 